\title{
Editorial
}

\section{Zur Erweiterung der Redaktion der Kritischen Justiz}

Schon bei der Feier zum 40-jährigen Jubiläum der Kritischen Justiz und bei der Konzeption und Realisierung des Sonderheftes 3/2008 hierfür haben sich fünf neue Redaktionsmitglieder ausgezeichnet, mit denen die Redaktion insgesamt verjüngt und ein produktiver Generationszusammenhang hergestellt wird. Sonja Buckel vom Institut für Politikwissenschaft in Frankfurt/Main steht für kritische Gesellschaftsforschung mit Schwerpunkten in materialistischer Rechtstheorie und europäischer Migrationskontrolle. Andreas Fischer-Lescano, Professor für öffentliches Recht, Europarecht, Völkerrecht und Rechtstheorie in Bremen, vereint theoretische und praktische Dimensionen vor allem auf dem Gebiet des Europa- und Völkerrechts, wo er schon seit langem bei fast allen zentralen Konflikten differenziert Stellung bezogen hat, gesellschaftstheoretisch, systemtheoretisch und rechtsdogmatisch. Felix Hanschmann vom Institut für ausländisches öffentliches Recht und Völkerrecht in Heidelberg bringt Erfahrungen aus seiner Tätigkeit beim »Dritten Senat « des Bundesverfassungsgerichts ein und wird sich dementsprechend vor allem mit den Grundlinien der rechts- und sozialstaatlichen Rechtsentwicklung von einem materialistischen Theoriefundament her befassen. Tanja Hitzel-Cassagnes vom Institut für Politische Wissenschaft der Universität Hannover hat Rechts-, Wirtschafts- und Politikwissenschaft studiert, über supranationale Gerichtsbarkeit promoviert und betrachtet kritisch vor allem die staatsrechtlichen Diskurse der europäischen Rechtsentwicklung mit ihren vertikalen und horizontalen Ebenen. Anne Lenze, Professorin für Familienrecht, Jugendrecht und Sozialrecht an der Hochschule Darmstadt, wie Fischer-Lescano in Frankfurt habilitiert, widmet sich vor allem den Interdependenzen von Sozialstaatsreform, Generationengerechtigkeit, Sozialversicherungs- und Steuerrecht. Die ältere Generation der Redaktionsmitglieder ist, von einzelnen Wechseln abgesehen, noch nicht abgetreten, hat die Arbeiten und Impulse der fünf Neuen aber nicht ohne einen gewissen Enthusiasmus aufgenommen, auch wenn sich durchaus tiefergehende Debatten über die gemeinsamen Grundlagen als notwendig erweisen sollten. In jedem Fall erscheinen Interdisziplinarität, Theorieanspruch und kritischer Impetus mit dieser Redaktionserweiterung für die nächste Zukunft gesichert.

Die Red. 